\title{
Phosphatases: The New Brakes for Cancer Development?
}

\author{
Qingxiu Zhang and Francois X. Claret \\ Department of Systems Biology, The University of Texas MD Anderson Cancer Center, 1515 Holcombe Boulevard, \\ Houston, TX 77030, USA \\ Correspondence should be addressed to Francois X. Claret, fxclaret@mdanderson.org
}

Received 22 July 2011; Revised 25 August 2011; Accepted 20 September 2011

Academic Editor: Assia Shisheva

Copyright () 2012 Q. Zhang and F. X. Claret. This is an open access article distributed under the Creative Commons Attribution License, which permits unrestricted use, distribution, and reproduction in any medium, provided the original work is properly cited.

\begin{abstract}
The phosphatidylinositol 3-kinase (PI3K) pathway plays a pivotal role in the maintenance of processes such as cell growth, proliferation, survival, and metabolism in all cells and tissues. Dysregulation of the PI3K/Akt signaling pathway occurs in patients with many cancers and other disorders. This aberrant activation of PI3K/Akt pathway is primarily caused by loss of function of all negative controllers known as inositol polyphosphate phosphatases and phosphoprotein phosphatases. Recent studies provided evidence of distinct functions of the four main phosphatases-phosphatase and tensin homologue deleted on chromosome 10 (PTEN), Src homology 2-containing inositol 5'-phosphatase (SHIP), inositol polyphosphate 4-phosphatase type II (INPP4B), and protein phosphatase $2 \mathrm{~A}(\mathrm{PP} 2 \mathrm{~A})$ - in different tissues with respect to regulation of cancer development. We will review the structures and functions of PTEN, SHIP, INPP4B, and PP2A phosphatases in suppressing cancer progression and their deregulation in cancer and highlight recent advances in our understanding of the PI3K/Akt signaling axis.
\end{abstract}

\section{Introduction}

The phosphatidylinositol (PI) 3-kinase (PI3K) signaling pathway is a normal signal transduction cascade that exists in all types of cells and is physiologically involved in cell proliferation, survival, protein synthesis, metabolism, differentiation, and motility. In physiological situations, many growth factors and regulators can stimulate or activate this pathway. The PI3K pathway contains the upstream PI3K, which phosphorylates the D-3 position of PI, PI 4-phosphate, and PI 4,5-bisphosphate $\left(\mathrm{PIP}_{2}\right)$ to produce PI 3-phosphate, PI 3,4bisphosphate $\left(\mathrm{PI}(3,4) \mathrm{P}_{2}\right)$, and $\mathrm{PI} 3,4,5$-trisphosphate $(\mathrm{PI}(3$, 4,5)P3 or $\mathrm{PIP}_{3}$ ), respectively [1], as well as Akt and its kinases PDK1, targets at Thr308 of Akt, and PDK2 which targets at Ser473 of Akt [2]. The second messengers of PIs are associated with major cellular functions such as growth, differentiation, apoptosis, protein trafficking, and motility. Several studies have identified inositol polyphosphate phosphatases, including three major PIP2/PIP $\mathrm{P}_{3}$-degrading enzymes: (1) phosphatase and tensin homologue deleted on chromosome 10 (PTEN), an ubiquitously expressed tumor suppressor that converts $\mathrm{PI}(3,4,5) \mathrm{P}_{3}$ to $\mathrm{PI}(4,5) \mathrm{P}_{2}$ by dephosphorylating the 3-position of PI(3,4,5)P3; (2) Src homology 2 (SH2)containing inositol $5^{\prime}$-phosphatase (SHIP), which dephosphorylates the 5-position $\mathrm{PI}(4,5) \mathrm{P} 3$ to produce $\mathrm{PI}(4) \mathrm{P}$ and hydrolyzes $\mathrm{PI}(3,4,5) \mathrm{P} 3$ to $\mathrm{PI}(3,4) \mathrm{P}_{2}$ phosphatase [3]; (3) inositol polyphosphate 4-phosphatase type II (INPP4B), which hydrolyzes the 4-position phosphates of $\mathrm{PI}(3,4) \mathrm{P}_{2}[4,5]$ and LKB1 [6] of the downstream tuberous sclerosis complex 2 (TSC2) $[7,8]$ and eukaryotic initiation factor 4E-(eIF4E) [9-11]. Besides these three major lipid phosphatases, other phosphatases inhibit the PI3K/Akt pathway, such as the serine/threonine phosphoprotein phosphatase (PPP) family member PP2A $[12,13]$. The PPP family has seven members: PP1, PP2A, PP2B (commonly known as calcineurin), PP4, PP5, PP6, and PP7. PP1 and PP2 are the most abundant and ubiquitous serine/threonine protein phosphatases in this family. To date, PP2A is the only known Akt-Thr308 phosphatase $[14,15]$. Unlike PP1 and PP2A, the in vitro basal activity of PP4, PP5, PP6, and PP7 is extremely low. PP2C (pleckstrin homology domain leucine-rich repeat protein phosphatase) belongs to a novel PP2C-type phosphatase family, the PPM subfamily. Pleckstrin homology domain leucine-rich repeat protein phosphatase functions as 
a "brake" for Akt and protein kinase C signaling, which has been extensively reviewed [16]. Herein we describe the structures of PTEN, SHIP, INPP4B, and PP2A phosphatases. We also characterize their functions in tumorigenesis and highlight our current knowledge of the PI3K/Akt pathway.

\section{PTEN}

2.1. PTEN Function: The Main Brake for Tumor Development. PTEN/MMAC (mutated in multiple advanced cancers), that controls negatively the PI3K/Akt pathway, is a tumor suppressor gene. PTEN normally inhibits PI3K/AKT activation by dephosphorylating $\mathrm{PIP}_{3}$ and $\mathrm{PIP}_{2}$, thus suppressing tumor formation [3, 17-19]. Two groups initially and simultaneously identified PTEN/MMAC as a candidate tumor suppressor gene located at 10q23 [20, 21]. Another group found that the protein transforming growth factor-(TGF-) $\beta$-regulated and epithelial cell-enriched phosphatase 1 encoded by the TEP1 gene is identical to the protein encoded by the candidate tumor suppressor gene PTEN/MMAC1 in a search for new dual-specificity phosphatases [22]. Loss of heterozygosity of PTEN at chromosome 10q22-25 occurs in multiple tumor types, most prominently advanced glial tumors (glioblastoma multiforme and anaplastic astrocytoma) but also prostate, endometrial, renal, and small cell lung carcinoma; melanoma; meningioma. Germline mutations in PTEN are present in cases of Cowden disease and Bannayan-Zonana syndrome, two related hereditary cancerpredisposition syndromes associated with elevated risk of breast and thyroid cancer $[23,24]$. Somatic mutations and biallelic inactivation of PTEN are frequently observed in high-grade glioblastomas, melanomas, and cancers of the prostate and endometrium, among others [25].

Loss of PTEN function leads to increased concentrations of $\mathrm{PIP}_{3}$, the main in vivo substrate of PTEN, resulting in constitutive activation of downstream components of the PI3K pathway, including the kinases AKT and mammalian target of rapamycin, mTOR [3]. One study found that $37(36 \%)$ of 103 endometrial cancers exhibited PTEN-negative immunohistochemical staining and a significant inverse correlation between expression of PTEN and that of phosphorylated AKT [26]. Another study has observed PTEN loss in both late- and early-stage melanoma cases [27]. In addition, an in vivo loss-of-function assay showed that $\mathrm{Pten}^{+/-}$mice experienced spontaneous development of tumors of various histological origins $[17,18]$. Moreover, PTEN inactivation dramatically enhanced the ability of embryonic stem cells to generate tumors in nude and syngeneic mice. An early study found only $2 \%$ of PTEN mutations in hormone receptorpositive breast cancers and identified about $20 \%$ of all PTEN mutations in breast cancer cell lines [28]. This suggested that PTEN mutation-associated cell lines are more viable in culture than patient tumors. Recent studies have shown that the frequencies of breast cancer cases associated with a loss of PTEN expression are, respectively, $30 \%$ in primary tumors and $25 \%$ in metastatic tumors [29], both higher values than those reported earlier by Stemke-Hale et al. [28]. Thus, regulation of PTEN expression at the posttranscriptional level plays a more critical role in breast cancer development compared to any genomic variations in PTEN. Besides breast cancers, researchers have characterized about $38 \%$ of patients with nonsmall cell lung cancer as having PTEN deletions/mutations [30]. Interestingly, Forgacs and colleagues have reported a relatively low frequency $(<10 \%)$ of somatic intragenic PTEN mutations in small-cell lung cancers and only two silent mutations and two apparent homozygous deletions in 22 primary small-cell lung cancer tumors and metastases [31]. Also, loss of heterozygosity of the PTEN/ $M M A C 1$ locus has been found in all histologic types of primary lung cancer [31]. More than 33\% of PTEN allelic deletions occurred before lung metastasis developed [32]. In prostate cancer, the rates of PTEN loss of heterozygosity have been much higher. Specifically, about $56 \%$ of prostate tumors have heterozygous alterations in PTEN at presentation, and about $90 \%$ of metastases have loss of the same allele [33].

In summary, PTEN performs differently in suppressing cancer progression in various tissues because of inconsistent occurrence of loss-of-function mutations.

\section{INPP4B}

INPP4B was initially isolated from rat brain and shown to be an enzyme that primarily hydrolyzes the 4-position phosphate of $\mathrm{PI}(3,4) \mathrm{P}_{2}$ into $\mathrm{PI}(3) \mathrm{P}$ in vivo and slightly hydrolyzes $\mathrm{PI}(3,4,5) \mathrm{P}_{3}$ in vitro $[34,35]$.

3.1. INPP4B Structure. Although the INPP4A $\alpha$ and INPP $4 \mathrm{~B} \alpha$ isoforms have hydrophilic $\mathrm{C}$-terminus regions, the INPP $4 \mathrm{~A} \beta$ and INPP $4 \mathrm{~B} \beta$ isoforms have hydrophobic Ctermini that contain potential transmembrane domains. Additionally, INPP4A and INPP4B share 37\% amino acid identity. The murine Inpp $4 b$ locus was mapped on chromosome 8 in a synthetic synthesized region of the human 4q27-31 interval between $\mathrm{Il}-15$ and Usp38. The murine INPP4B proteins include the $\alpha$ and $\beta$ isoforms encoded by this locus. These two isoforms contain 927 and 941 amino acids, respectively, with consensus phosphatase catalytic sites and conserved C2 domains that are highly similar to those of the human and rat homologues. The C2 domain at the Nterminus of INPP4B is the lipid-binding domain. The Nervy homology 2 domain is the internal domain as well as a Cterminal phosphatase domain. Human and murine INPP4B C2 lipid-binding domains share greater than $91 \%$ sequence identity [36]. The murine INPP4B- $\alpha$ and $-\beta$ spliced isoforms are highly conserved and have different expression patterns and cell localization [36].

3.2. INPP4B and Cancer. Increasing evidence has confirmed that INPP4B is a tumor suppressor gene. Westbrook and colleagues identified INPP $4 B$ as a tumorigenesis-restraining gene in a nonbiased RNA interference-based screen for genes with functional relevance to tumor initiation and development that suppress transformation of human mammary epithelial cells [37]. INPP4B expression was silenced in malignant proerythroblasts; these cells displayed increased levels of phosphorylated Akt expression that could be reduced by 
reexpression of INPP4B [38]. The INPP4B locus is located on chromosome $4 \mathrm{q} 31.21$, a region that is frequently deleted in breast cancer cell lines and high-grade basal-like breast tumors as determined using high-resolution comparative genomic hybridization analysis [39-41]. These findings have been further supported by subsequent studies. Loss of heterozygosity of INPP4B is frequently observed in BRCA1mutant and hormone receptor-negative breast cancer cells. Loss of INPP4B protein expression in breast and ovarian cancer cells is associated with decreased patient survival rates. In human mammary epithelial cells and breast cancer cell lines, INPP4B was able to suppress both basal [5] and insulin-like growth factor-induced Akt phosphorylation [4]. Further evidence of INPP4B as a tumor suppressor gene comes from a nonbiased RNAi-based genetic screen. The loss of INPP4B promotes the anchorage-independent growth of human mammary epithelial cells [37]. In particular, INPP4B protein expression is lost in $84 \%$ of human basallike breast carcinomas, which are generally highly aggressive with poor clinical outcomes and frequently associated with $B R C A 1$ gene mutations [42]. Authors have reported that INPP4B is expressed in nonproliferative estrogen receptor(ER-)positive normal breast cells and breast cancer cell lines but not in ER-negative breast cancer cell lines [4]. Furthermore, INPP4B knockdown in ER-positive breast cancer cells increased Akt activation, cell proliferation, and xenograft tumor growth. Conversely, reexpression of INPP4B in ERnegative, INPP4 $\mathrm{B}^{-/-}$human breast cancer cells reduced Akt activation and anchorage-independent growth [4]. In the same study, INPP4B protein expression was frequently lost in primary human breast carcinoma cells, associated with high clinical grade and large tumors and loss of expression of hormone receptors, and lost most often in aggressive basallike breast carcinomas [4]. INPP4B protein expression was also frequently lost in PTEN-null tumors [5]. Androgenablation therapies in the treatment of advanced prostate cancers are associated with increased Akt signaling [43]. Androgens, therefore, play an important role in control of the proliferation of prostate epithelial cells, through the downregulation of Akt signaling. Activated-Akt signaling stimulates cellular proliferation, cell survival, cell cycle progression, growth, migration, and angiogenesis [44]. The expression of INPP4B, which dephosphorylates $\mathrm{PI}(3,4) \mathrm{P}_{2}$ and inactivates Akt and inhibits cellular proliferation, was substantially lower in primary prostate tumors than that in normal prostate tissue $[45,46]$. Levels of INPP4B are found to be induced by the androgen receptor in prostate cancer cells and play an important role in androgen-ablation therapy of prostate cancers [45]. The INPP4B expression levels should be taken in consideration when Androgenablation therapies are utilized for patients with advanced prostate cancers.

\section{SHIP}

The cDNA-encoding isoform of the $145-\mathrm{kD}$ protein SHIP (also called SHIP1) was initially cloned from a murine hematopoietic cell line and named B6SUtAI. B6SUtAI was then identified as the novel SH2-containing inositol polyphosphate 5-phosphatase SHIP. SHIP specifically hydrolyzes PIP $_{3}$ and inositol 1,3,4,5-tetraphosphate [47]. The same group identified and cloned human SHIP and mapped it to the long arm of chromosome 2 at the border between 2q36 and 2q37 [48].

4.1. SHIP1 Structure and Function. SHIP1 contains 1190 amino acids and several identifiable motifs important for protein-protein interactions, including an $\mathrm{N}$-terminal $\mathrm{SH} 2$ domain, a central $5^{\prime}$-phosphoinositol phosphatase domain, two phosphotyrosine binding consensus sequences, and a proline-rich region at the carboxyl tail. Human SHIP shares $87.2 \%$ sequence identity with mSHIP [48].

SHIP is expressed ubiquitously in differentiated cells in the hematopoietic system [47, 49, 50], endothelial cells [51], hematopoietic stem cells, and embryonic stem cells [52]. Particularly, SHIP1 can be phosphorylated at the tyrosine of the first NPXY motif located in the N-terminal SH2 domain [53, $54]$ in response to activation of hematopoietic cell surface receptors, such as erythropoietin, steel factor, interleukin$3[55,56]$, interleukin-2, granulocyte-macrophage colonystimulating factor, and macrophage colony-stimulating factor, by numerous cytokines [57]. In one study, the number of granulocyte-macrophage progenitors in both the bone marrow and spleen increased in SHIP1-knockout mice [58, 59]. SHIP1 is essential for normal bone homeostasis, as absence of SHIP1 results in severe osteoporosis [60]. SHIP1 also reduces the proliferation of osteoclasts via Akt-dependent alterations in D-type cyclins and p27 [61].

SHIP1 is an antagonist of cell growth and proliferation in the hematopoietic system. Investigators first verified SHIP1 as a tumor suppressor in conditional B-cell PTEN/SHIP1 knockout mice. They established B-cell-specific deletion of both Pten and Ship (bPTEN/SHIP ${ }^{-/-}$) by mating bPTEN ${ }^{-/-}$ mice with a novel strain of mice lacking SHIP only in B cells $\left(\mathrm{bSHIP}^{-/-}\right)$. The mice lacking expression of PTEN and SHIP in B cells develop lethal B-cell lymphomas with similarities to human mature B-cell lymphomas. Loss of both PTEN and SHIP expression in B cells results in an aggressive, often fatal B-cell lymphoma disease. All B-cell PTEN/SHIP1-knockout mice died by 1 year of age [62], thus, suggesting that SHIP1 and PTEN coordinately suppress B lymphoma development.

4.2. SHIP2 Structure and Function. The SHIP isozyme SHIP2, also named INPPL1, is a $155-\mathrm{kD}$ phosphatase that is more widely expressed than is SHIP1 [63]. The SHIP2 cDNA was initially cloned from skeletal muscle, and the lipid phosphatase that hydrolyzes the $5^{\prime}$-phosphate of the inositol ring from in $\mathrm{PIP}_{3}$ was identified. SHIP2 is more broadly detected than SHIP1, which is mainly expressed in hematopoietic cells [64]. Human SHIP2 is highly expressed in adult heart, skeletal muscle, and placenta. SHIP2 regulates insulin signaling, and genetic SHIP2 knockout prevents dietinduced obesity in mice [65]. SHIP2 also regulates cytoskeleton remodeling and receptor endocytosis. In another study, SHIP2 expression was elevated in $44 \%$ of clinical breast tumor specimens [66]. Furthermore, SHIP2 is a positive 
regulator of the epidermal growth factor receptor/Akt pathway, C-X-C chemokine receptor type 4 expression, and cell migration in MDA-MB-231 breast cancer cells [67].

Despite the potential microRNAs (miRNAs) to regulate approximately one third of the entire genome, relatively few miRNA targets SHIP2 have been validated experimentally, particularly in stratified squamous epithelia. Yu and colleagues showed that miRNA-205 suppresses the expression of lipid phosphatase SHIP2 in epithelial cells [68]. They found that SHIP2 levels correlate reciprocally with elevated miRNA-205 levels in aggressive squamous cell carcinoma (SCC) cells. Downregulation of miRNA-205 expression in squamous cell carcinoma cells leads to decreased phosphorylated Akt and phosphorylated Bcl-2-associated death promoter expression and increased apoptosis [68]. The function of miRNA-205 in SHIP2 expression is negatively regulated by miRNA-184 in keratinocytes. Downregulation of miRNA-205 expression by ectopic expression of miRNA184 increases SHIP2 expression and impairs the ability of keratinocytes wound healing. Keratinocytes not only express the epidermal growth factor (EGF) receptor but also produce ligands for this receptor, including TGF- $\alpha$, amphiregulin, and HB-EGF. EGF and TGF- $\alpha$ promote keratinocyte proliferation and migration [69]. Many cellular processes, such as altered cell adhesion, expression of matrix-degrading proteinases, and cell migration, are common to keratinocytes during wound healing and in metastatic tumors. Yu and colleagues provided abundant evidence that SHIP2 is involved in keratinocyte migration promoted by miRNA-205 [70].

\section{PP2A}

PP2A is a major serine/threonine protein phosphatase in mammalian cells. It accounts for up to $1 \%$ of all cellular proteins and, together with PP1, accounts for $90 \%$ of all serine/threonine phosphatase activity in most tissues and cells [71]. PP2A is highly conserved from yeast to humans, and its regulatory mechanism is extraordinarily complex.

5.1. PP2A Structure and Function. Several holoenzyme complexes of PP2A have been isolated from a variety of tissues and extensively characterized. The core enzyme of PP2A is a dimer (PP2AD) consisting of a $65-\mathrm{kD}$ scaffolding A subunit (also termed PR65/A and PP2R) and a 36-kD catalytic C or A subunit. The scaffolding A $\alpha$ subunit of PP2A contains 15 Huntington, elongation factor 3, a subunit of PP2A, and target of rapamycin 1 repeats [72]. The third regulatory $\mathrm{B}$ subunit of PP2A, which includes at least 18 regulatory subunits that have been classified B (B55 or PR55), B' (B56 or PR61), $\mathrm{B}^{\prime \prime}$ (PR48/PR72/PR130), and B"' (PR93/PR110), is associated with the core enzyme. Studies identified a unique C-terminal tail (residues 294-309) in PP2A's C subunit, which contains a motif (TPDY307FL309) that is highly conserved and exists in the catalytic subunits of all PP2Alike phosphatases, including PP4 and PP6. Methylation of Leu309 in this C-terminal tail can promote recruitment of the regulatory $\mathrm{B} / \mathrm{B}^{\prime} / \mathrm{B}^{\prime \prime}$ subunits to the $\mathrm{A} / \mathrm{C}$ dimer [73]. The Huntington, elongation factor 3 , a subunit of PP2A, and target of rapamycin 1 repeats in the scaffold A subunit play roles in holding the catalytic $\mathrm{C}$ and regulatory $\mathrm{B}^{\prime}$ subunits together. To date, researchers have identified five primary members of the B56 family $(\alpha, \beta, \gamma, \delta$, and $\varepsilon)$ that are encoded by different genes-PPP2R5A, PPP2R5B, PPP2R5C, PPP2R5D, and PPP2R5E-which are mapped to the loci 1q41, 11q12, 3p21, 6p21.1, and 7p11.2, respectively [74]. B56 subunits of PP2A share a highly conserved central region of $80 \%$ identity (which comprises two A-subunit binding domains). These regulatory B subunits play key roles in controlling PP2A substrate specificity, cellular localization, and enzymatic activity [75]. These regulatory subunits are expressed in specific tissues and lead to the formation of different PP2A complexes mammalian tissues [76]. In comparison, three subunits of B56 family-B56 $\beta, B 56 \delta$, and B56ع - exist primarily in the brain, whereas two othersB56alpha and B56gamma-are highly expressed in cardiac and skeletal tissue [74]. PP2A expression is regulated by both C-terminal methylation and phosphorylation of the C subunit residue Tyr307; tyrosine kinases such as Src inhibit PP2A activity [77], and phosphorylation of the B56 subunit by Erk inhibits PP2A assembly [78].

The active core dimer of PP2A interacts with a wide variety of regulatory subunits (B subunits) and generates more than 60 different heterotrimeric PP2A holoenzymes that dictate the functions of individual forms. These regulatory subunits typically increase the formation of stable complexes of PP2A with its substrates. PP2A has the remarkable ability to interact with structurally distinct regulatory subunits and form complexes with many different substrates owing to the inherent flexibility of the scaffold subunit A, which is composed of 15 tandem HEAT repeats. These 60 holoenzymes catalyze distinct dephosphorylation events that result in specific functional outcomes [79]. PP2A complexes have been implicated in regulation of the mitogen-activated protein kinase, Wnt, PI3K, nuclear factor- $\kappa \mathrm{B}$, protein kinase $\mathrm{C}$, and $\mathrm{Ca}^{2+} /$ calmodulin-dependent signaling pathways as well as downstream targets of these and other pathways. In most pathways, the specific constituents of the regulatory PP2A complexes have yet to be determined. PP2A dephosphorylates multiple components of these signaling pathways in vitro, and increasing in vivo evidence supports the physiological relevance of many of these interactions [80].

5.2. PP2A and Cancer. The role of the tumor suppressor PP2A in controlling tumor progression is thought to be governed by a small subset of specific B subunits directing PP2A to dephosphorylate and regulate key tumor suppressors or oncogenes [76, 81]. Indeed, several members of the B56 family have been described as having a role in directing PP2A's tumor-suppressive activity. PP2A was initially identified as a tumor suppressor in studies in which okadaic acid was found to be a potent carcinoma inducer in a mouse model (Figure 1) [82]. Okadaic acid was also found to be selective inhibitor of PP2A activity in these studies. Ito and colleagues observed that N-terminally truncated B56 $\gamma$ leads to enhanced invasiveness and neoplastic progression, transforming melanoma cells from a nonmetastatic to a metastatic 


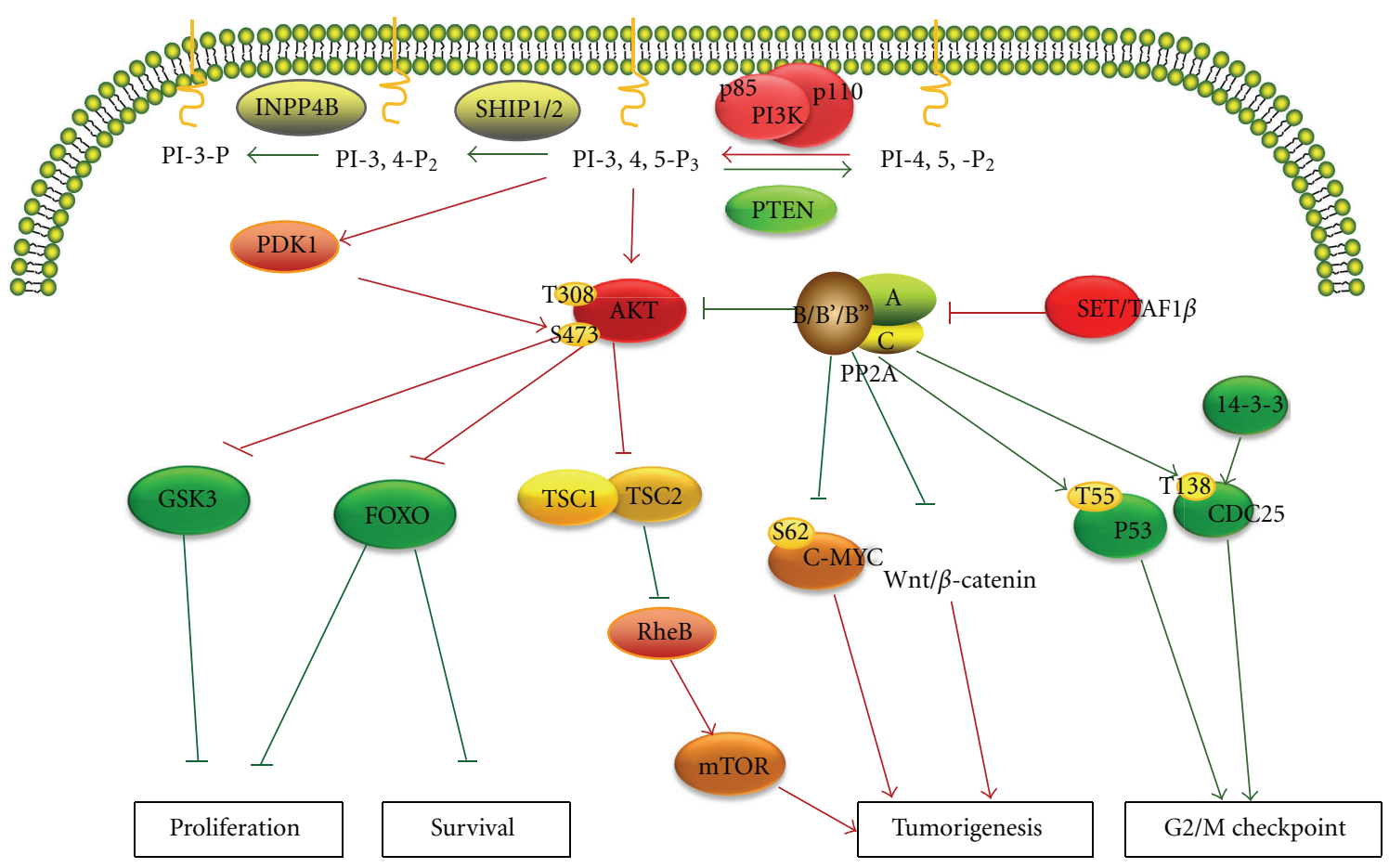

FIGURE 1: The primary phosphatases function as tumor suppressors and their signaling pathways. This model demonstrates the roles of PTEN, INPP4B, SHIP1/2, and PP2A in regulation of signaling downstream of PI3K/Akt. Two major phospholipid pools-PI(3,4,5)P3 and $\mathrm{PI}(3,4) \mathrm{P} 2$ - were generated in response to stimulation of PI3K. PTEN hydrolyzed the $3^{\prime}$-phosphate of PI $(3,4,5) \mathrm{P} 3$ to terminate PI3K signaling. SHIP family members hydrolyzed the $5^{\prime}$-phosphate of $\mathrm{PI}(3,4,5) \mathrm{P} 3$ to generate $\mathrm{PI}(3,4) \mathrm{P} 2$, which, like $\mathrm{PI}(3,4,5) \mathrm{P} 3$, can facilitate PDK1-dependent phosphorylation and activation of AKT. INPP4B converted PI(3,4)P2 to PI(3)P. PP2A not only dephosphorylated Akt at T308 and S473 and negatively regulated the PI3K/Akt pathway but also stabilized p53 or CDC25 and the 14-3-3 complex, inactivated the oncoprotein c-Myc, and antagonized the $\mathrm{Wnt} / \beta$-catenin pathway. Red arrows indicate enhancing tumorigenesis activities, and green arrows indicate inhibition of tumorigenesis.

state [83]. Further evidence supporting PP2A as a tumor suppressor comes from the finding that the small-t antigen (ST) in two transforming DNA viruses, SV40 and polyoma virus, causes cell transformation by binding to regulatory subunits $\mathrm{A}$ and $\mathrm{C}$ of PP2A and displacing a single PP2A regulatory subunit (B56y) from PP2A complexes. This interaction is essential for ST to transform cells $[84,85]$. Another study confirmed PP2A to be the target of the adenoviral protein E4orf4. It further suggested that PP2A, like other targets of viral oncoproteins, plays an important role in tumor suppression [86]. Mechanistically, downregulation of PP2A expression by ST stabilizes the phosphorylation of proteins such as c-Myc at Ser62 and p53 at either Thr55 or Ser37 and causes cells to undergo uncontrolled growth [87-89]. Chen and colleagues found that specific suppression of the B56y subunit replaced ST of SV40 or polyoma virus and induced cell anchorage-independent growth and tumor formation [87]. The $\mathrm{B}^{\prime} / \mathrm{B} 56 / \mathrm{PR} 61 \gamma$ subunit of PP2A is involved in tumor formation. In addition, partial knockdown of expression of the PP2A $\alpha$ subunit results in selective loss of PP2A heterotrimers containing the B56y subunit, and loss of B56y from PP2A complexes substitutes for the small tumor antigen during transformation, as well. The partial suppression of endogenous $\mathrm{A} \alpha$ leads to activation of Akt kinase, suggesting that activation of the PI3K/Akt pathway contributes to transformation. In addition, PP2A is involved in cell transformation as an important tumor suppressor [79]. Loss-of-function screening on PP2A by short hairpin RNA recognized that PP2A C $\alpha$ involved in the SV40 small T-antigen caused human cell transformation but not $C \beta$ subunits or the PP2A regulatory subunits B56 $\alpha, \mathrm{B} 56 \delta$, and PR72/PR130. Further evidence of PP2A as tumor suppressor comes from the finding that inhibition of PP2A expression by short hairpin RNA activates the PI3K/Akt and c-Myc signaling pathways [90].

Although mutations of PP2A A $\alpha$ occur at low frequencies in human tumors, mutations of the second PP2A A subunit, $\mathrm{A} \beta$, are more common. Specifically, researchers found somatic alterations, including point mutations, deletions, frameshifts, and splicing abnormalities, of the PPP $2 R 1 B$ gene, which encodes the PR65/A scaffold protein, in 15\% of primary lung tumors, $6 \%$ of lung tumor-derived cell lines, $13 \%$ of breast tumors, and $15 \%$ of primary colon tumors. Missense mutations and homozygous deletions of the same gene were found in $8 \%$ of patients and $2 \%$ of patients, respectively, with colorectal cancer [91-94]. These cancerassociated PP2A A $\beta$ mutants are defective in binding to $\mathrm{B}$ and/or $C$ subunits in vitro [95]. In addition to mutations of it, the PP2A A $\beta$ gene is located at 11q23, a chromosomal region frequently deleted in cancer cells [96]. Also, PPP2R1A 
encoding the $\alpha$-isoform of the scaffolding subunit of the serine/threonine PP2A holoenzyme was recently found to be mutated in 7\% (3/42) of patients with ovarian clear cell carcinoma [97]. Somatic missense mutations of PPP2R1A have been demonstrated in $41 \%$ (20/49) of high-grade serous endometrial tumors and $5 \%(3 / 60)$ of endometrial endometrioid carcinomas. Another study identified mutations of PPP2R1A in ovarian tumors but at lower frequencies: $12 \%$ of endometrioid carcinomas and $4 \%$ of clear cell carcinomas [98]. Very recently, the PPP2R5E gene, which encodes a regulatory subunit of $\mathrm{PP} 2 \mathrm{~A}$, was identified as harboring genetic variants that affect soft tissue sarcoma [99].

5.3. PP2A as a Tumor Suppressor. Researchers found that PPP2R1A and PPP2R5E mutations interfered with the binding of specific third regulatory B subunits of PP2A [95]. For example, Damuni's group identified SET as one of the heatstable PP2A protein inhibitors that induce leukemogenesis. SET, also called template-activating factor $1 \beta$ or phosphatase $2 \mathrm{~A}$ inhibitor 2 , is a nuclear phosphoprotein. SET was first identified in a patient with acute nonlymphocytic myeloid leukemia [100]. The SET gene is fused to CAN [101]. SET expression is high in rapidly dividing cells but low in quiescent and contact-inhibited cells. SET contributes to tumorigenesis in part by forming an inhibitory protein complex with PP2A [100]. Amino acid residues affected by these mutations are highly conserved across species and interact directly with regulatory B subunits of the PP2A holoenzyme. Additionally, investigators found the B56 $\gamma$ mutation F395C, which is located in the B56 $\gamma$-p53 binding domain, in lung cancer cells. This mutation impairs the functions of B56 $\gamma$ PP2A in dephosphorylation of p53 at Thr55 [102].

Furthermore, B56ع (encoded by PPP2R5E), a B56-family-regulatory subunit of PP2A, can trigger p53-dependent apoptosis. Mechanistically, B56 $\varepsilon$ regulates the p53-dependent apoptotic pathway solely by controlling the stability of the p53 protein [103].

$\mathrm{PP} 2 \mathrm{~A}$ reportedly antagonizes the $\mathrm{Wnt} / \beta$-catenin pathway via physical interaction of B56 subunits with Wnt pathway components. In addition, treatment of HEK 293 cells with okadaic acid, an inhibitor of PP2A, results in elevated $\beta$ catenin protein expression [104]. Overexpression of PP2A: $B 56 \varepsilon$ inhibits $\mathrm{Wnt} / \beta$-catenin signaling in tissue culture and Xenopus embryos [104-106]. Loss-of-function analysis of PP2A: B56ع during early Xenopus embryogenesis showed that PP2A: B56e is required for $\mathrm{Wnt} / \beta$-catenin signaling [107]. The $\mathrm{B}^{\prime} / \mathrm{B} 56 / \mathrm{PR} 61$ subunit binds to the tumor suppressor adenomatous polyposis coli, which is a component of the Wnt pathway. The Wnt pathway plays essential roles during embryonic development and tumorigenesis [108, 109]. B56 $\alpha$-PP2A can dephosphorylate c-Myc at Ser62 and inactivate the oncoprotein c-Myc $[110,111]$. The protein cancerous inhibitor of PP2A interacts directly with the oncogenic transcription factor $\mathrm{c}-\mathrm{Myc}$ by inhibiting the catalytic activity of the PP2A holoenzyme toward c-Myc at Ser62, thereby preventing c-Myc proteolytic degradation without affecting PP2A binding potential [112].
$\mathrm{PP} 2 \mathrm{~A}$ is involved in regulation of DNA-responsive G2/M checkpoints, as well. DNA-responsive checkpoints activate PP2A/B56 $\delta$ phosphatase complexes to dephosphorylate CDC25 at sites different from Ser287 (Thr138), phosphorylation of which is required for release of 14-3-3 protein from CDC25. Ser287 phosphorylation is a major locus of G2/M checkpoint control. B56 $\delta$ C-PP2A promotes Thr138 dephosphorylation and prevents 14-3-3 release. This restricts PP1 recruitment, CDC25 activation, and entry of cells from G2 to $\mathrm{M}$ phase. Remarkably, the CHK1 kinase activated during the replication checkpoint phosphorylates B56 $\delta$, enhancing its incorporation into PP2A holoenzyme. Therefore, B56 $\delta$-PP2A dephosphorylates Cdc25, blocking cell-cycle progression as a central checkpoint effector $[113,114]$. However, whether PP2A/B56 $\delta$ phosphatase complexes are involved in DNA repair must be clarified.

In other experiments, researchers identified B56-containing PP2As to be phosphatases of Akt and found that PP2A reverses immediate early response gene $\mathrm{X}-1$-mediated Akt activation [115]. Immediate early response gene X-1, also known as IER3, DIF2, and Gly96, is an ubiquitous early response gene product involved in cell proliferation and survival. The cell proliferation and survival is rapidly induced in response to various growth factors, cytokines, chemical carcinogens, and viral infections [116]. Vereshchagina and colleagues found that the protein phosphatase PP2A- $\mathrm{B}^{\prime}$ subunit Widerborst acts as a subcellular compartment-specific regulator of PI3K/PTEN/Akt kinase signalling and negatively regulates cytoplasmic Akt activity in Drosophila [117]. A more recent study confirmed that $\mathrm{B} 56 \beta$ (PPP2R5B, $\mathrm{B}^{\prime} \beta$ ) plays a critical role in the assembly of the PP2A holoenzyme complex on Akt, which leads to dephosphorylation of both Ser473 and Thr308 Akt sites. However, Cdc2-like kinase 2 phosphorylates the $\mathrm{PP} 2 \mathrm{~A}$ regulatory subunit B56 $\beta$ and triggers the assembly procession of $\mathrm{PP} 2 \mathrm{~A}$ holoenzyme complex and subsequently downregulates Akt activity [118]. Moreover, a study identified PP2A (encoded by PPP2R5E) along with BIM (Bcl2L11), an AMP-activated kinase (encoded by Prkaa1), and the tumor suppressor phosphatase PTEN as the targets of miRNA-19 in Notch-induced acute T-cell leukemia cells [119].

In general, the genetic and epigenetic changes in $\mathrm{PP} 2 \mathrm{~A}$ complexes in human cancer cells remain to be defined, as does their impact on cancer signaling and therapeutic responses to targeted therapy. One of the PP2A-regulated cancer signaling pathways is the mammalian target of rapamycin pathway, a key component of the PI3K pathway that many cancer cells are "addicted" for growth.

\section{Conclusion}

SHIP1/2, PP2A, INPP4B, and PTEN are commonly viewed as opposing the activity of the PI3K/Akt signaling axis, which promotes survival of cancer cells and tumors. It is certain that the enzymatic activities of $3^{\prime}$ polyphosphatase work as negative controller. Most powerfully, PTEN downregulates PI3K's reaction by converting $\mathrm{PI}(3,4,5) \mathrm{P}_{3}$ to $\mathrm{PI}(4,5) \mathrm{P}_{2}$. Whereas the $5^{\prime}$ polyphosphatase activity of SHIP $1 / 2$ converts $\mathrm{PI}(3,4,5) \mathrm{P}_{3}$ 
to $\mathrm{PI}(3,4) \mathrm{P} 2$. This distinction is potentially crucial, as it may enable SHIP1/2 and PTEN to have distinctly different effects on Akt signaling. PTEN expression is a relatively ubiquitous negative regulator of the PI3K/Akt signaling pathway. Lossof-function PTEN mutation/deletions lead to the development of all types of cancer. SHIP1 is specifically expressed in all cells of the hematopoietic system and is correlated with T- and B-cell lymphoma development. SHIP2 functions as a positive regulator of the epidermal growth factor receptor/ Akt pathway, C-X-C chemokine receptor type 4 expression, and cell migration in breast cancer cells but a negative regulator of keratinocyte migration. INPP4B specifically hydrolyzes $\mathrm{PI}(3,4) \mathrm{P} 2$ to be $\mathrm{PI}(3) \mathrm{P}$, negatively regulates the PI3K/Akt pathway, and has emerged as a potential tumor suppressor in prostate, breast, and ovarian cancers and, possibly, leukaemias. PP2A, as a tumor suppressor, is more complicated than other phosphatases because it has five regulatory subunits that exist in different tissues and play different roles in various cells. These five subunits are inclined to be mutated and affect their own function. Most of the mutations of these five subunits remain unidentified. How PTEN, SHIP1/2, INPP4B, and PP2A orchestrate to sustain normal signaling and achieve efficient inhibition of the PI3K/Akt pathway in all types of cells and tissues is still far from being completely determined.

\section{Conflict of Interests}

The authors declared that there is no conflict of interests.

\section{Acknowledgments}

The authors thank Maria M. Georgescu, Ling Tian, and Thuy $\mathrm{T}$. Vu for providing helpful comments on the paper. They thank Don Norwood for editing this paper. The authors acknowledge the financial support given by the National Cancer Institute (CA90853-01A1), U.S. Department of Defense, and the Susan G. Komen for the Cure to Francois X. Claret.

\section{References}

[1] T. F. Franke, D. R. Kaplan, and L. C. Cantley, "PI3K: downstream AKTion blocks apoptosis," Cell, vol. 88, no. 4, pp. 435-437, 1997.

[2] B. T. Hennessy, D. L. Smith, P. T. Ram, Y. Lu, and G. B. Mills, "Exploiting the PI3K/AKT pathway for cancer drug discovery," Nature Reviews Drug Discovery, vol. 4, no. 12, pp. 988-1004, 2005.

[3] A. Di Cristofano and P. P. Pandolfi, "The multiple roles of PTEN in tumor suppression," Cell, vol. 100, no. 4, pp. 387$390,2000$.

[4] C. Gewinner, Z. C. Wang, A. Richardson et al., "Evidence that inositol polyphosphate 4-phosphatase type II is a tumor suppressor that inhibits PI3K signaling," Cancer Cell, vol. 16, no. 2, pp. 115-125, 2009.

[5] C. G. Fedele, L. M. Ooms, M. Ho et al., "Inositol polyphosphate 4-phosphatase II regulates PI3K/Akt signaling and is lost in human basal-like breast cancers," Proceedings of the National Academy of Sciences of the United States of America, vol. 107, no. 51, pp. 22231-22236, 2010.

[6] J. Boudeau, G. Sapkota, and D. R. Alessi, "LKB1, a protein kinase regulating cell proliferation and polarity," FEBS Letters, vol. 546, no. 1, pp. 159-165, 2003.

[7] D. J. Kwiatkowski, "Rhebbing up mTOR: new insights on TSC1 and TSC2, and the pathogenesis of tuberous sclerosis," Cancer Biology \& Therapy, vol. 2, no. 5, pp. 471-476, 2003.

[8] B. D. Manning and L. C. Cantley, "United at last: the tuberous sclerosis complex gene products connect the phosphoinositide 3-kinase/Akt pathway to mammalian target of rapamycin (mTOR) signalling," Biochemical Society Transactions, vol. 31, no. 3, pp. 573-578, 2003.

[9] S. Avdulov, S. Li, V. Michalek et al., "Activation of translation complex eIF4F is essential for the genesis and maintenance of the malignant phenotype in human mammary epithelial cells," Cancer Cell, vol. 5, no. 6, pp. 553-563, 2004.

[10] D. Ruggero, L. Montanaro, L. Ma et al., "The translation factor eIF-4E promotes tumor formation and cooperates with c-Myc in lymphomagenesis," Nature Medicine, vol. 10, no. 5, pp. 484-486, 2004.

[11] H. G. Wendel, E. De Stanchina, J. S. Fridman et al., "Survival signalling by Akt and eIF4E in oncogenesis and cancer therapy," Nature, vol. 428, no. 6980, pp. 332-337, 2004.

[12] G. Manning, D. B. Whyte, R. Martinez, T. Hunter, and S. Sudarsanam, "The protein kinase complement of the human genome," Science, vol. 298, no. 5600, pp. 1912-1934, 2002.

[13] Y. Shi, "Assembly and structure of protein phosphatase 2A," Science in China, Series C, vol. 52, no. 2, pp. 135-146, 2009.

[14] T. A. Millward, S. Zolnierowicz, and B. A. Hemmings, "Regulation of protein kinase cascades by protein phosphatase 2A," Trends in Biochemical Sciences, vol. 24, no. 5, pp. 186-191, 1999.

[15] T. Gao, F. Furnari, and A. C. Newton, "PHLPP: a phosphatase that directly dephosphorylates Akt, promotes apoptosis, and suppresses tumor growth," Molecular Cell, vol. 18, no. 1, pp. 13-24, 2005.

[16] J. Brognard and A. C. Newton, "PHLiPPing the switch on Akt and protein kinase C signaling," Trends in Endocrinology and Metabolism, vol. 19, no. 6, pp. 223-230, 2008.

[17] A. Di Cristofano, B. Pesce, C. Cordon-Cardo, and P. P. Pandolfi, "Pten is essential for embryonic development and tumour suppression," Nature Genetics, vol. 19, no. 4, pp. 348355, 1998.

[18] V. Stambolic, A. Suzuki, J. L. De la Pompa et al., "Negative regulation of $\mathrm{PKB} / \mathrm{Akt}$-dependent cell survival by the tumor suppressor PTEN," Cell, vol. 95, no. 1, pp. 29-39, 1998.

[19] X. Wu, K. Senechal, M. S. Neshat, Y. E. Whang, and C. L. Sawyers, "The PTEN/MMAC1 tumor suppressor phosphatase functions as a negative regulator of the phosphoinositide 3-kinase/Akt pathway," Proceedings of the National Academy of Sciences of the United States of America, vol. 95, no. 26, pp. 15587-15591, 1998.

[20] J. Li, C. Yen, D. Liaw et al., "PTEN, a putative protein tyrosine phosphatase gene mutated in human brain, breast, and prostate cancer," Science, vol. 275, no. 5308, pp. 1943-1947, 1997.

[21] P. A. Steck, M. A. Pershouse, S. A. Jasser et al., "Identification of a candidate tumour suppressor gene, MMAC1, at chromosome 10q23.3 that is mutated in multiple advanced cancers," Nature Genetics, vol. 15, no. 4, pp. 356-362, 1997.

[22] D. M. Li and H. Sun, "TEP1, encoded by a candidate tumor suppressor locus, is a novel protein tyrosine phosphatase 
regulated by transforming growth factor $\beta$," Cancer Research, vol. 57, no. 11, pp. 2124-2129, 1997.

[23] D. Liaw, D. J. Marsh, J. Li et al., "Germline mutations of the PTEN gene in Cowden disease, an inherited breast and thyroid cancer syndrome," Nature Genetics, vol. 16, no. 1, pp. 64-67, 1997.

[24] D. J. Marsh, P. L. Dahia, Z. Zheng et al., "Germline mutations in PTEN are present in Bannayan-Zonana syndrome," Nature Genetics, vol. 16, no. 4, pp. 333-334, 1997.

[25] I. Sansal and W. R. Sellers, "The biology and clinical relevance of the PTEN tumor suppressor pathway," Journal of Clinical Oncology, vol. 22, no. 14, pp. 2954-2963, 2004.

[26] N. Terakawa, Y. Kanamori, and S. Yoshida, "Loss of PTEN expression followed by Akt phosphorylation is a poor prognostic factor for patients with endometrial cancer," Endocrine-Related Cancer, vol. 10, no. 2, pp. 203-208, 2003.

[27] H. Wu, V. Goel, and F. G. Haluska, "PTEN signaling pathways in melanoma," Oncogene, vol. 22, no. 20, pp. 3113-3122, 2003.

[28] K. Stemke-Hale, A. M. Gonzalez-Angulo, A. Lluch et al., "An integrative genomic and proteomic analysis of PIK3CA, PTEN, and AKT mutations in breast cancer," Cancer Research, vol. 68, no. 15, pp. 6084-6091, 2008.

[29] A. M. Gonzalez-Angulo, J. Ferrer-Lozano, K. Stemke-Hale et al., "PI3K pathway mutations and PTEN levels in primary and metastatic breast cancer," Molecular Cancer Therapeutics, vol. 10, no. 6, pp. 1093-1101, 2011.

[30] S. Regina, J. B. Valentin, S. Lachot, E. Lemarié, J. Rollin, and Y. Gruel, "Increased tissue factor expression is associated with reduced survival in non-small cell lung cancer and with mutations of TP53 and PTEN," Clinical Chemistry, vol. 55, no. 10, pp. 1834-1842, 2009.

[31] E. Forgacs, E. J. Biesterveld, Y. Sekido et al., "Mutation analysis of the PTEN/MMAC1 gene in lung cancer," Oncogene, vol. 17, no. 12, pp. 1557-1565, 1998.

[32] Y. Hosoya, A. Gemma, M. Seike et al., "Alteration of the PTEN/MMAC1 gene locus in primary lung cancer with distant metastasis," Lung Cancer, vol. 25, no. 2, pp. 87-93, 1999.

[33] H. Suzuki, D. Freije, D. R. Nusskern et al., "Interfocal heterogeneity of PTEN/MMAC1 gene alterations in multiple metastatic prostate cancer tissues," Cancer Research, vol. 58, no. 2, pp. 204-209, 1998.

[34] F. A. Norris, E. Ungewickell, and P. W. Majerus, "Inositol hexakisphosphate binds to clathrin assembly protein 3 (AP3/AP180) and inhibits clathrin cage assembly in vitro," The Journal of Biological Chemistry, vol. 270, no. 1, pp. 214-217, 1995.

[35] F. A. Norris, R. C. Atkins, and P. W. Majerus, "The cDNA cloning and characterization of inositol polyphosphate 4phosphatase type II. Evidence for conserved alternative splicing in the 4-phosphatase family," The Journal of Biological Chemistry, vol. 272, no. 38, pp. 23859-23864, 1997.

[36] M. Ferron and J. Vacher, "Characterization of the murine Inpp4b gene and identification of a novel isoform," Gene, vol. 376, no. 1-2, pp. 152-161, 2006.

[37] T. F. Westbrook, E. S. Martin, M. R. Schlabach et al., "A genetic screen for candidate tumor suppressors identifies REST," Cell, vol. 121, no. 6, pp. 837-848, 2005.

[38] S. Barnache, E. Le Scolan, O. Kosmider, N. Denis, and F. Moreau-Gachelin, "Phosphatidylinositol 4-phosphatase type II is an erythropoietin-responsive gene," Oncogene, vol. 25, no. 9, pp. 1420-1423, 2006.

[39] T. L. Naylor, J. Greshock, Y. Wang et al., "High resolution genomic analysis of sporadic breast cancer using array-based comparative genomic hybridization," Breast Cancer Research, vol. 7, no. 6, pp. R1186-R1198, 2005.

[40] A. Bergamaschi, Y. H. Kim, P. Wang et al., "Distinct patterns of DNA copy number alteration are associated with different clinicopathological features and gene-expression subtypes of breast cancer," Genes Chromosomes and Cancer, vol. 45, no. 11, pp. 1033-1040, 2006.

[41] S. F. Chin, Y. Wang, N. P. Thorne et al., "Using array-comparative genomic hybridization to define molecular portraits of primary breast cancers," Oncogene, vol. 26, no. 13, pp. 1959-1970, 2007.

[42] E. A. Rakha, S. E. El-Sheikh, M. A. Kandil, M. E. El-Sayed, A. R. Green, and I. O. Ellis, "Expression of BRCA1 protein in breast cancer and its prognostic significance," Human Pathology, vol. 39, no. 6, pp. 857-865, 2008.

[43] Y. Wang, J. I. Kreisberg, and P. M. Ghosh, "Cross-talk between the androgen receptor and the phosphatidylinositol 3kinase/Akt pathway in prostate cancer," Current Cancer Drug Targets, vol. 7, no. 6, pp. 591-604, 2007.

[44] T. L. Yuan and L. C. Cantley, "PI3K pathway alterations in cancer: variations on a theme," Oncogene, vol. 27, no. 41, pp. 5497-5510, 2008.

[45] M. C. Hodgson, L.-J. Shao, A. Frolov et al., "Decreased expression and androgen regulation of the tumor suppressor gene INPP4B in prostate cancer," Cancer Research, vol. 71, no. 2, pp. 572-582, 2011.

[46] I. U. Agoulnik, M. C. Hodgson, W. A. Bowden, and M. M. Ittmann, "INPP4B: the new kid on the PI3K block," Oncotarget, vol. 2, no. 4, pp. 321-328, 2011.

[47] J. E. Damen, L. Liu, P. Rosten et al., "The 145-kDa protein induced to associate with She by multiple cytokines is an inositol tetraphosphate and phosphatidylinositol 3,4,5trisphosphate 5-phosphatase," Proceedings of the National Academy of Sciences of the United States of America, vol. 93, no. 4, pp. 1689-1693, 1996.

[48] M. D. Ware, P. Rosten, J. E. Damen, L. Liu, R. K. Humphries, and G. Krystal, "Cloning and characterization of human SHIP, the 145-kD inositol 5-phosphatase that associates with SHC after cytokine stimulation," Blood, vol. 88, no. 8, pp. 2833-2840, 1996.

[49] W. G. Kerr, M. Heller, and L. A. Herzenberg, "Analysis of lipopolysaccharide-response genes in B-lineage cells demonstrates that they can have differentiation stage-restricted expression and contain SH2 domains," Proceedings of the National Academy of Sciences of the United States of America, vol. 93, no. 9, pp. 3947-3952, 1996.

[50] M. N. Lioubin, P. A. Algate, S. Tsai, K. Carlberg, R. Aebersold, and L. R. Rohrschneider, "p150Ship, a signal transduction molecule with inositol polyphosphate-5-phosphatase activity," Genes and Development, vol. 10, no. 9, pp. 1084-1095, 1996.

[51] A. Zippo, A. De Robertis, M. Bardelli, F. Galvagni, and S. Oliviero, "Identification of Flk-1 target genes in vasculogenesis: Pim-1 is required for endothelial and mural cell differentiation in vitro," Blood, vol. 103, no. 12, pp. 45364544, 2004.

[52] Z. Tu, J. M. Ninos, Z. Ma et al., "Embryonic and hematopoietic stem cells express a novel SH2-containing inositol 5'phosphatase isoform that partners with the Grb2 adapter protein," Blood, vol. 98, no. 7, pp. 2028-2038, 2001.

[53] N. Gupta, A. M. Scharenberg, D. A. Fruman, L. C. Cantley, J. P. Kinet, and E. O. Long, "The $\mathrm{SH} 2$ domain-containing inositol $5^{\prime}$-phosphatase (SHIP) recruits the p85 subunit of 
phosphoinositide 3-kinase during Fc $\gamma$ RIIb1-mediated inhibition of B cell receptor signaling," The Journal of Biological Chemistry, vol. 274, no. 11, pp. 7489-7494, 1999.

[54] D. M. Lucas and L. R. Rohrschneider, "A novel spliced form of SH2-containing inositol phosphatase is expressed during myeloid development," Blood, vol. 93, no. 6, pp. 1922-1933, 1999.

[55] L. Liu, J. E. Damen, M. D. Ware, and G. Krystal, "Interleukin3 induces the association of the inositol 5-phosphatase SHIP with SHP2," The Journal of Biological Chemistry, vol. 272, no. 17, pp. 10998-11001, 1997.

[56] R. L. Cutler, L. Liu, J. E. Damen, and G. Krystal, "Multiple cytokines induce the tyrosine phosphorylation of Shc and its association with Grb2 in hemopoietic cells," The Journal of Biological Chemistry, vol. 268, no. 29, pp. 21463-21465, 1993.

[57] M. N. Lioubin, G. M. Myles, K. Carlberg, D. Bowtell, and L. R. Rohrschneider, "Shc, Grb2, Sos1, and a 150-kilodalton tyrosine-phosphorylated protein form complexes with Fms in hematopoietic cells," Molecular and Cellular Biology, vol. 14, no. 9, pp. 5682-5691, 1994.

[58] L. M. Sly, V. Ho, F. Antignano et al., "The role of SHIP in macrophages," Frontiers in Bioscience, vol. 12, pp. 2836-2848, 2007.

[59] C. P. Baran, S. Tridandapani, C. D. Helgason, R. K. Humphries, G. Krystal, and C. B. Marsh, "The inositol 5'-phosphatase SHIP-1 and the Src kinase Lyn negatively regulate macrophage colony-stimulating factor-induced Akt activity," The Journal of Biological Chemistry, vol. 278, no. 40, pp. 38628-38636, 2003.

[60] C. D. Helgason, J. E. Damen, P. Rosten et al., "Targeted disruption of SHIP leads to hemopoietic perturbations, lung pathology, and a shortened life span," Genes and Development, vol. 12, no. 11, pp. 1610-1620, 1998.

[61] P. Zhou, H. Kitaura, S. L. Teitelbaum, G. Krystal, F. P. Ross, and S. Takeshita, "SHIP1 negatively regulates proliferation of osteoclast precursors via Akt-dependent alterations in Dtype cyclins and p27," Journal of Immunology, vol. 177, no. 12, pp. 8777-8784, 2006.

[62] A. V. Miletic, A. N. Anzelon-Mills, D. M. Mills et al., "Coordinate suppression of B cell lymphoma by PTEN and SHIP phosphatases," The Journal of Experimental Medicine, vol. 207, no. 11, pp. 2407-2420, 2010.

[63] L. M. Sly, M. J. Rauh, J. Kalesnikoff, T. Büchse, and G. Krystal, "SHIP, SHIP2, and PTEN activities are regulated in vivo by modulation of their protein levels: SHIP is up-regulated in macrophages and mast cells by lipopolysaccharide," Experimental Hematology, vol. 31, no. 12, pp. 1170-1181, 2003.

[64] S. Schurmans, R. Carrió, J. Behrends, V. Pouillon, J. Merino, and S. Clément, "The mouse SHIP2 (Inppl1) gene: complementary DNA, genomic structure, promoter analysis, and gene expression in the embryo and adult mouse," Genomics, vol. 62 , no. 2, pp. 260-271, 1999.

[65] S. Clément, U. Krause, F. Desmedt et al., "The lipid phosphatase SHIP2 controls insulin sensitivity," Nature, vol. 409, no. 6816, pp. 92-97, 2001.

[66] N. K. Prasad, M. Tandon, A. Handa et al., "High expression of obesity-linked phosphatase SHIP2 in invasive breast cancer correlates with reduced disease-free survival," Tumor Biology, vol. 29, no. 5, pp. 330-341, 2008.

[67] N. K. Prasad, M. Tandon, S. Badve, P. W. Snyder, and H. Nakshatri, "Phosphoinositol phosphatase SHIP2 promotes cancer development and metastasis coupled with alterations in EGF receptor turnover," Carcinogenesis, vol. 29, no. 1, pp. 25-34, 2008.
[68] J. Yu, D. G. Ryan, S. Getsios, M. Oliveira-Fernandes, A. Fatima, and R. M. Lavker, "MicroRNA-184 antagonizes microRNA-205 to maintain SHIP2 levels in epithelia," Proceedings of the National Academy of Sciences of the United States of America, vol. 105, no. 49, pp. 19300-19305, 2008.

[69] Y. Barrandon and H. Green, "Cell migration is essential for sustained growth of keratinocyte colonies: the roles of transforming growth factor- $\alpha$ and epidermal growth factor," Cell, vol. 50, no. 7, pp. 1131-1137, 1987.

[70] J. Yu, H. Peng, Q. Ruan, A. Fatima, S. Getsios, and R. M. Lavker, "MicroRNA-205 promotes keratinocyte migration via the lipid phosphatase SHIP2," The FASEB Journal, vol. 24, no. 10, pp. 3950-3959, 2010.

[71] X. H. Lin, J. Walter, K. Scheidtmann, K. Ohst, J. Newport, and G. Walter, "Protein phosphatase 2A is required for the initiation of chromosomal DNA replication," Proceedings of the National Academy of Sciences of the United States of America, vol. 95, no. 25, pp. 14693-14698, 1998.

[72] R. Ruediger, M. Hentz, J. Fait, M. Mumby, and G. Walter, "Molecular model of the A subunit of protein phosphatase 2A: interaction with other subunits and tumor antigens," Journal of Virology, vol. 68, no. 1, pp. 123-129, 1994.

[73] X. X. Yu, X. Du, C. S. Moreno et al., "Methylation of the protein phosphatase $2 \mathrm{~A}$ catalytic subunit is essential for association of $\mathrm{B} \alpha$ regulatory subunit but not SG2NA, striatin, or polyomavirus middle tumor antigen," Molecular Biology of the Cell, vol. 12, no. 1, pp. 185-199, 2001.

[74] B. McCright, A. R. Brothman, and D. M. Virshup, "Assignment of human protein phosphatase $2 \mathrm{~A}$ regulatory subunit genes B56 $\alpha, \mathrm{B} 56 \beta, \mathrm{B} 56 \gamma, \mathrm{B} 56 \delta$, and B56e (PPP2R5APPP2R5E), highly expressed in muscle and brain, to chromosome regions 1q41, 11q12, 3p21, 6p21.1, and 7p11.2 $\rightarrow$ p12," Genomics, vol. 36, no. 1, pp. 168-170, 1996.

[75] U. S. Cho, S. Morrone, A. A. Sablina, J. D. Arroyo, W. C. Hahn, and W. Xu, "Structural basis of PP2A inhibition by small t antigen," PLoS Biology, vol. 5, no. 8, p. e202, 2007.

[76] D. M. Virshup and S. Shenolikar, "From promiscuity to precision: protein phosphatases get a makeover," Molecular Cell, vol. 33, no. 5, pp. 537-545, 2009.

[77] J. Chen, B. L. Martin, and D. L. Brautigan, "Regulation of protein serine-threonine phosphatase type-2A by tyrosine phosphorylation," Science, vol. 257, no. 5074, pp. 1261-1264, 1992.

[78] C. Letourneux, G. Rocher, and F. Porteu, "B56-containing PP2A dephosphorylate ERK and their activity is controlled by the early gene IEX-1 and ERK," The EMBO Journal, vol. 25, no. 4, pp. 727-738, 2006.

[79] M. Mumby, "PP2A: unveiling a reluctant tumor suppressor," Cell, vol. 130, no. 1, pp. 21-24, 2007.

[80] J. D. Arroyo and W. C. Hahn, "Involvement of PP2A in viral and cellular transformation," Oncogene, vol. 24, no. 52, pp. 7746-7755, 2005.

[81] P. J. A. Eichhorn, M. P. Creyghton, and R. Bernards, "Protein phosphatase 2A regulatory subunits and cancer," Biochimica et Biophysica Acta, vol. 1795, no. 1, pp. 1-15, 2009.

[82] M. Suganuma, H. Fujiki, H. Suguri et al., "Okadaic acid: an additional non-phorbol-12-tetradecanoate-13-acetatetype tumor promoter," Proceedings of the National Academy of Sciences of the United States of America, vol. 85, no. 6, pp. 1768-1771, 1988.

[83] A. Ito, Y. I. Koma, and K. Watabe, "A mutation in protein phosphatase type $2 \mathrm{~A}$ as a cause of melanoma progression," Histology and Histopathology, vol. 18, no. 4, pp. 1313-1319, 2003. 
[84] W. C. Hahn, S. K. Dessain, M. W. Brooks et al., "Enumeration of the simian virus 40 early region elements necessary for human cell transformation," Molecular and Cellular Biology, vol. 22, no. 7, pp. 2111-2123, 2002.

[85] J. Yu, A. Boyapati, and K. Rundell, "Critical role for SV40 small-t antigen in human cell transformation," Virology, vol. 290, no. 2, pp. 192-198, 2001.

[86] A. H. Schönthal, "Role of serine/threonine protein phosphatase 2A in cancer," Cancer Letters, vol. 170, no. 1, pp. 1-13, 2001.

[87] W. Chen, R. Possemato, K. T. Campbell, C. A. Plattner, D. C. Pallas, and W. C. Hahn, "Identification of specific PP2A complexes involved in human cell transformation," Cancer Cell, vol. 5, no. 2, pp. 127-136, 2004.

[88] K. M. Dohoney, C. Guillerm, C. Whiteford et al., "Phosphorylation of p53 at serine 37 is important for transcriptional activity and regulation in response to DNA damage," Oncogene, vol. 23, no. 1, pp. 49-57, 2004.

[89] H. H. Li, X. Cai, G. P. Shouse, L. G. Piluso, and X. Liu, "A specific PP2A regulatory subunit, B56 $\gamma$, mediates DNA damage-induced dephosphorylation of p53 at Thr55," The EMBO Journal, vol. 26, no. 2, pp. 402-411, 2007.

[90] A. A. Sablina, M. Hector, N. Colpaert, and W. C. Hahn, "Identification of PP2A complexes and pathways involved in cell transformation," Cancer Research, vol. 70, no. 24, pp. 10474-10484, 2010.

[91] S. S. Wang, E. D. Esplin, J. L. Li et al., "Alterations of the PPP2R1B gene in human lung and colon cancer," Science, vol. 282, no. 5387, pp. 284-287, 1998.

[92] G. A. Calin, M. G. Di Iasio, E. Caprini et al., "Low frequency of alterations of the $\alpha$ (PPP2R1A) and $\beta$ (PPP2R1B) isoforms of the subunit $\mathrm{A}$ of the serine-threonine phosphatase $2 \mathrm{~A}$ in human neoplasms," Oncogene, vol. 19, no. 9, pp. 1191-1195, 2000.

[93] R. Ruediger, H. T. Pham, and G. Walter, "Alterations in protein phosphatase $2 \mathrm{~A}$ subunit interaction in human carcinomas of the lung and colon with mutations in the $\mathrm{A} \beta$ subunit gene," Oncogene, vol. 20, no. 15, pp. 1892-1899, 2001.

[94] M. Tamaki, T. Goi, Y. Hirono, K. Katayama, and A. Yamaguchi, "PPP2R1B gene alterations inhibit interaction of PP2A-Abeta and PP2A-C proteins in colorectal cancers," Oncology Reports, vol. 11, no. 3, pp. 655-659, 2004.

[95] R. Ruediger, H. T. Pham, and G. Walter, "Disruption of protein phosphatase 2 a subunit interaction in human cancers with mutations in the A $\alpha$ subunit gene," Oncogene, vol. 20, no. 1, pp. 10-15, 2001.

[96] B. E. Baysal, J. E. Willett-Brozick, P. E. M. Taschner, J. G. Dauwerse, P. Devilee, and B. Devlin, "A high-resolution integrated map spanning the SDHD gene at 11q23: a 1.1$\mathrm{Mb}$ BAC contig, a partial transcript map and 15 new repeat polymorphisms in a tumour-suppressor region," European Journal of Human Genetics, vol. 9, no. 2, pp. 121-129, 2001.

[97] S. Jones, T. L. Wang, I. M. Shih et al., "Frequent mutations of chromatin remodeling gene ARID1A in ovarian clear cell carcinoma," Science, vol. 330, no. 6001, pp. 228-231, 2010.

[98] M. K. McConechy, M. S. Anglesio, S. E. Kalloger et al., "Subtype-specific mutation of PPP2R1A in endometrial and ovarian carcinomas," Journal of Pathology, vol. 223, no. 5, pp. 567-573, 2011.

[99] L. F. Grochola, A. Vazquez, E. E. Bond et al., "Recent natural selection identifies a genetic variant in a regulatory subunit of protein phosphatase $2 \mathrm{~A}$ that associates with altered cancer risk and survival," Clinical Cancer Research, vol. 15, no. 19, pp. 6301-6308, 2009.

[100] M. Li, A. Makkinje, and Z. Damuni, "The myeloid leukemiaassociated protein SET is a potent inhibitor of protein phosphatase 2A," The Journal of Biological Chemistry, vol. 271, no. 19, pp. 11059-11062, 1996.

[101] M. von Lindern, S. van Baal, J. Wiegant, A. Raap, A. Hagemeijer, and G. Grosveld, "can, a putative oncogene associated with myeloid leukemogenesis, may be activated by fusion of its $3^{\prime}$ half to different genes: characterization of the set gene," Molecular and Cellular Biology, vol. 12, no. 8, pp. 3346-3355, 1992.

[102] G. P. Shouse, Y. Nobumori, and X. Liu, "A B56 $\gamma$ mutation in lung cancer disrupts the p53-dependent tumor-suppressor function of protein phosphatase 2A," Oncogene, vol. 29, no. 27, pp. 3933-3941, 2010.

[103] Z. Jin, L. Wallace, S. Q. Harper, and J. Yang, "PP2A:B56e, a substrate of caspase-3, regulates p53-dependent and p53independent apoptosis during development," The Journal of Biological Chemistry, vol. 285, no. 45, pp. 34493-34502, 2010.

[104] J. M. Seeling, J. R. Miller, R. Gil, R. T. Moon, R. White, and D. M. Virshup, "Regulation of $\beta$-catenin signaling by the B56 subunit of protein phosphatase 2A," Science, vol. 283, no. 5410, pp. 2089-2091, 1999.

[105] Z. H. Gao, J. M. Seeling, V. Hill, A. Yochum, and D. M. Virshup, "Casein kinase I phosphorylates and destabilizes the $\beta$-catenin degradation complex," Proceedings of the National Academy of Sciences of the United States of America, vol. 99, no. 3, pp. 1182-1187, 2002.

[106] X. Li, H. J. Yost, D. M. Virshup, and J. M. Seeling, "Protein phosphatase 2A and its B56 regulatory subunit inhibit Wnt signaling in Xenopus," The EMBO Journal, vol. 20, no. 15, pp. 4122-4131, 2001.

[107] J. Yang, J. Wu, C. Tan, and P. S. Klein, "PP2A: B56E is required for Wnt/ $\beta$-catenin signaling during embryonic development," Development, vol. 130, no. 23, pp. 5569-5578, 2003.

[108] X. He, M. Semenov, K. Tamai, and X. Zeng, "LDL receptorrelated proteins 5 and 6 in $\mathrm{Wnt} / \beta$-catenin signaling: arrows point the way," Development, vol. 131, no. 8, pp. 1663-1677, 2004.

[109] B. T. MacDonald, K. Tamai, and X. He, "Wnt/ $\beta$-catenin signaling: components, mechanisms, and diseases," Developmental Cell, vol. 17, no. 1, pp. 9-26, 2009.

[110] E. Yeh, M. Cunningham, H. Arnold et al., "A signalling pathway controlling c-Myc degradation that impacts oncogenic transformation of human cells," Nature Cell Biology, vol. 6, no. 4, pp. 308-318, 2004.

[111] H. K. Arnold and R. C. Sears, "Protein phosphatase 2A regulatory subunit B56 $\alpha$ associates with c-Myc and negatively regulates c-Myc accumulation," Molecular and Cellular Biology, vol. 26, no. 7, pp. 2832-2844, 2006.

[112] M. R. Junttila, P. Puustinen, M. Niemelä et al., "CIP2A inhibits PP2A in human malignancies," Cell, vol. 130, no. 1, pp. 51-62, 2007.

[113] S. S. Margolis, J. A. Perry, C. M. Forester et al., "Role for the PP2A/B56 $\delta$ phosphatase in regulating 14-3-3 release from Cdc25 to control mitosis," Cell, vol. 127, no. 4, pp. 759-773, 2006.

[114] C. M. Forester, J. Maddox, J. V. Louis, J. Goris, and D. M. Virshup, "Control of mitotic exit by PP2A regulation of Cdc25C and Cdk1," Proceedings of the National Academy of Sciences of the United States of America, vol. 104, no. 50, pp. 19867-19872, 2007. 
Enzyme Research

11

[115] G. Rocher, C. Letourneux, P. Lenormand, and F. Porteu, "Inhibition of B56-containing protein phosphatase As by the early response gene IEX-1 leads to control of Akt activity," The Journal of Biological Chemistry, vol. 282, no. 8, pp. 54685477, 2007.

[116] M. X. Wu, "Roles of the stress-induced gene IEX-1 in reguration of cell death and oncogenesis," Apoptosis, vol. 8, no. 1, pp. 11-18, 2003.

[117] N. Vereshchagina, M. C. Ramel, E. Bitoun, and C. Wilson, “The protein phosphatase PP2A-B' subunit Widerborst is a negative regulator of cytoplasmic activated Pkt and lipid metabolism in Drosophila," Journal of Cell Science, vol. 121, no. 20, pp. 3383-3392, 2008.

[118] J. T. Rodgers, R. O. Vogel, and P. Puigserver, "Clk2 and B56 $\beta$ mediate insulin-regulated assembly of the PP2A phosphatase holoenzyme complex on Att," Molecular Cell, vol. 41, no. 4, pp. 471-479, 2011.

[119] K. J. Mavrakis, A. L. Wolfe, E. Oricchio et al., "Genome-wide RNA-mediated interference screen identifies miR-19 targets in Notch-induced T-cell acute lymphoblastic leukaemia," Nature Cell Biology, vol. 12, no. 4, pp. 372-379, 2010. 

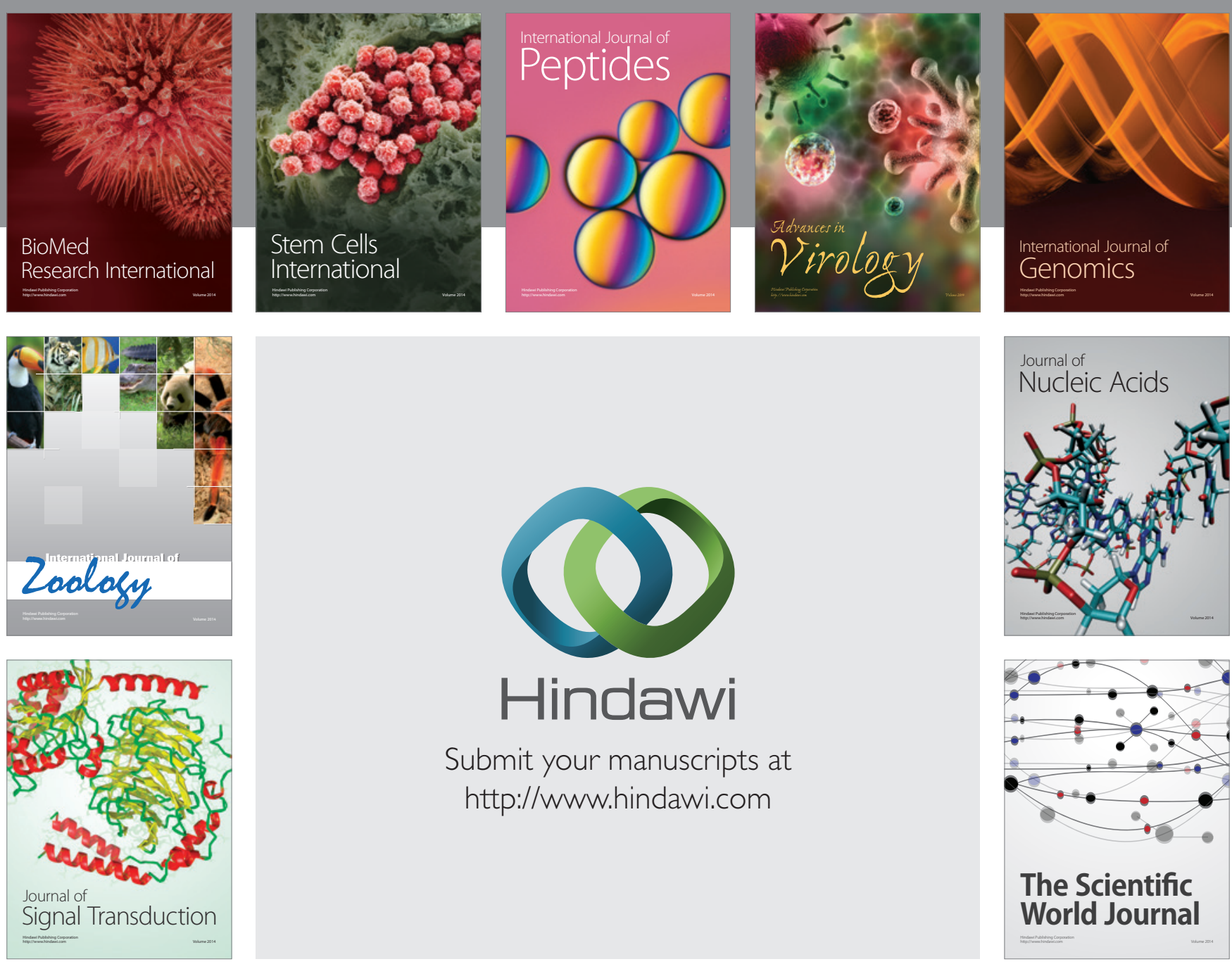

Submit your manuscripts at

http://www.hindawi.com
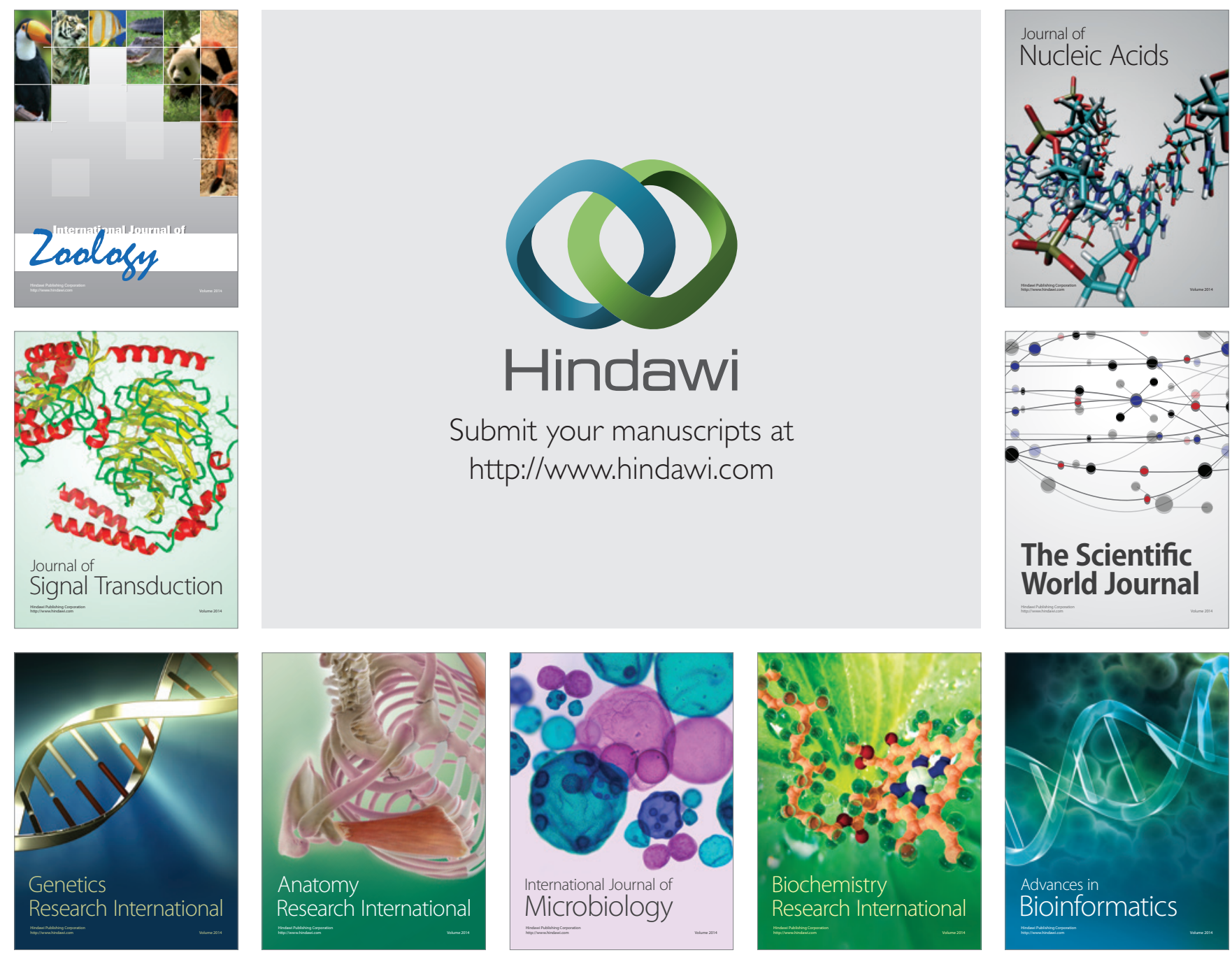

The Scientific World Journal
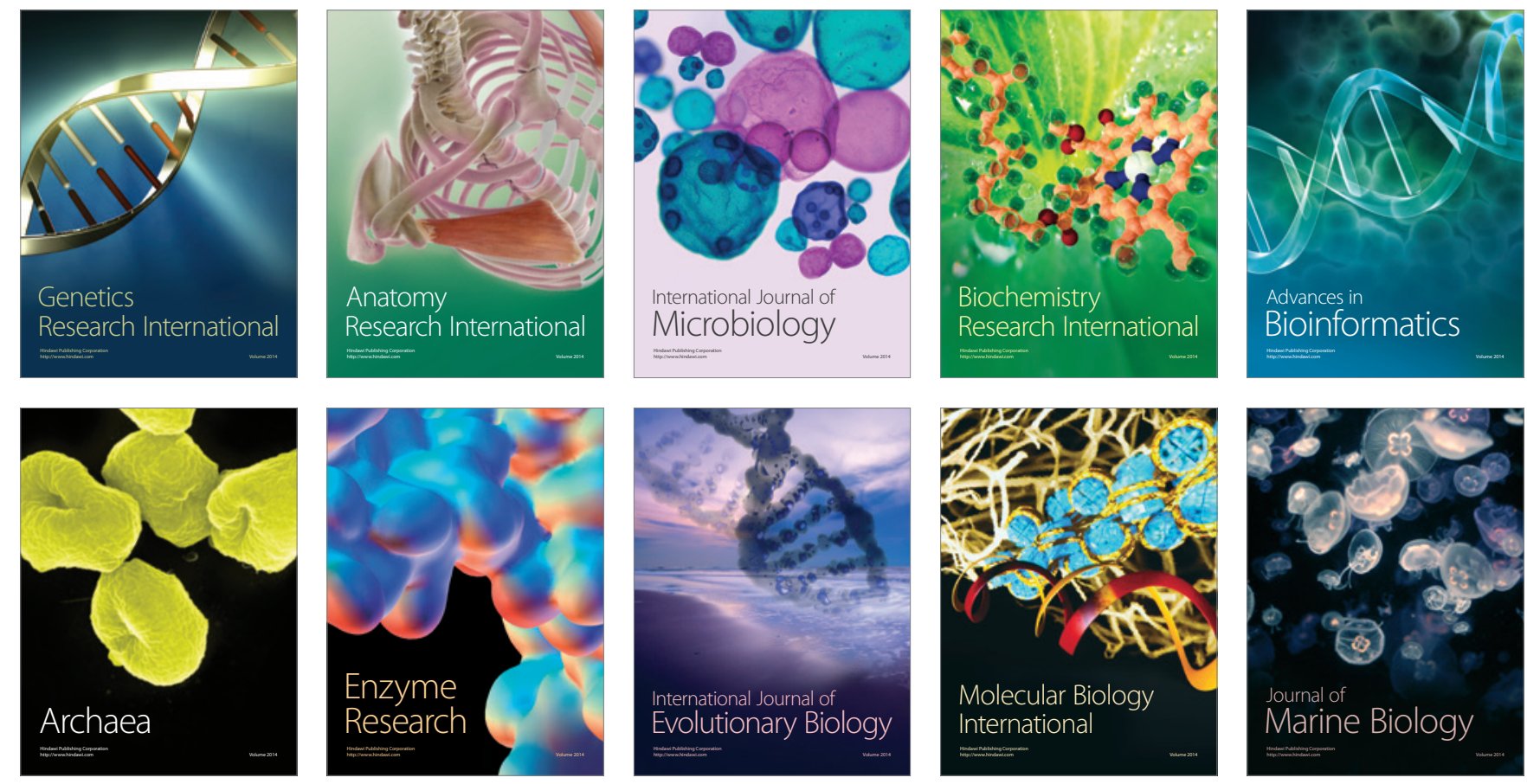